\title{
Study on nonlinear multiaxial fatigue damage and reliability of TC4 titanium alloy for aeroengine blades
}

\author{
Bingqiang $\mathrm{Li}^{1}$, Honggen Zhou ${ }^{1}$, Jinfeng Liu ${ }^{1}$, and Chao Kang ${ }^{1}$ \\ ${ }^{1}$ Affiliation not available
}

October 19, 2020

\begin{abstract}
In order to study the fatigue damage and cycle life of TC4 titanium alloy for aero-engine blades under various load conditions, uniaxial fatigue, multi-stage loading and multiaxial fatigue tests were carried out. The critical plane method combined with von Mises criterion was used to study the fatigue life distribution under various loading paths, and the results were verified by experiments. Based on the nonlinear residual strength model and Poisson stochastic process, the reliability prediction of aero-engine compressor blade under maximum continuous working condition was completed. The results show that the fatigue damage and life distribution of TC4 titanium alloy for aeroengine blade under various conditions can be accurately predicted by the method proposed in this paper and the reliability of the blade can still be maintained above 0.9 after it works for 3000 hours under the maximum continuous working condition.
\end{abstract}

\section{Hosted file}

manuscript-fin3.pdf available at https://authorea.com/users/366639/articles/487528-studyon-nonlinear-multiaxial-fatigue-damage-and-reliability-of-tc4-titanium-alloy-foraeroengine-blades 